NASA Technical Memorandum 89909

AIAA-87-9442

\title{
Impact of Thermal Energy Storage Properties on Solar Dynamic Space Power Conversion System Mass
}

\begin{abstract}
Albert J. Juhasz, Carolyn E. Coles-Hamilton, and Dovie E. Lacy Lewis Research Center

Cleveland, Ohio
\end{abstract}

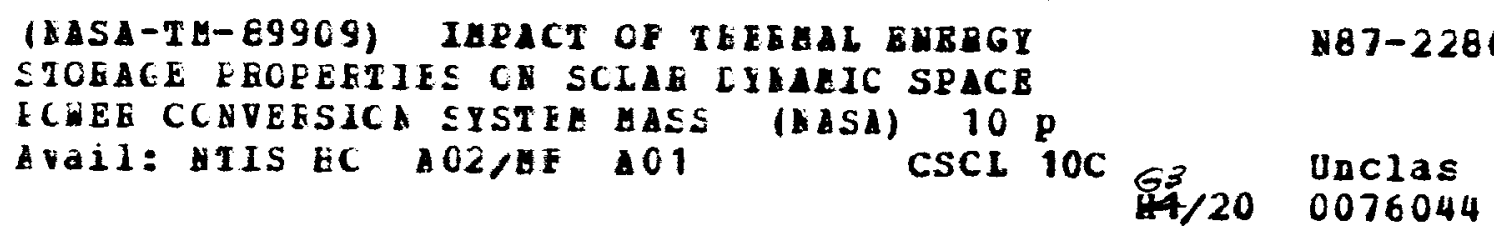

Prepared for the

22nd Intersociety Energy Conversion Engineering Conference cosponsored by the AIAA, ANS, ASME, SAE, IEEE, ACS, and AIChE Philadelphia, Pennsylvania, August 10-14, 1987

\section{N/SN}


IMPACT OF THERMAL ENERGY STORAGE PROPERTIES ON SOLAR DYNAMIC SPACE POWER CONVERSION SYSTEM MASS

Albert J. Juhasz, Carolyn E. Coles-Hamilton, and Dovie E. Lacy

National Aeronautics and Space Administration

Lewis Research Center

Cleveland, Ohio 44135

\section{Abstract}

A sixteen parameter solar concentrator/heat receiver mass model is used in conjunction with Stirling and Brayton Power Conversion System (PCS) performance and mass computer codes to determine the effect of thermal energy storage (TES) material property changes on overall PCS mass as a function of steady state electrical power output. Included in the PCS mass model are component masses as a function of thermal power for: concentrator, heat receiver, heat exchangers, heat engine units with optional parallel redundancy, power conditioning and control ( $P C C), P C$ and $C$ radiator, main radiator, and structure. Critical TES material properties considered are: melting temperature, heat of fusion, density of the liquid phase, and the ratio of solid-to-riquid density.

Preliminary results indicate that the overall system efficiency increases with melting temperature up to $1400 \mathrm{~K}$ for concentrator surface accuracies of $1 \mathrm{mrad}$ or better. Reductions in the overall system mass beyond that achievable using a baseline TES material, salt-lithium fluoride ( $L i F$ ), may be accomplished if metallic TES materials with heats of fusion of at least $800 \mathrm{~kJ} / \mathrm{kg}$ and liquid densities comparable to that of $L i F(1874)$ are used. Moreover, the identification of suitable combinations of TES eutectics with high heats of fusion and comparable densities may also result in lighter weight systems than the baseline LiF.

\section{Introduction}

Solar dynamic power systems offer the potential for efficient, lightweight, survivable, relatively compact, long-lived space power systems applicable to a wide range of power levels ( 3 to $100 \mathrm{kWe})$, and a variety of orbits. The successful development of these systems could satisfy the power needs for many of the projected NASA, Civil, Commercial, and Military missions. These systems, which offer a nonnuclear aiternative to the SP-100 reactor power systems, are competitive with alternate solar PV technologies in the very small sizes but become increasingly attractive for higher power applications ( 50 to $100 \mathrm{kWe}$ ) where increased efficiency, compact size, and reduced drag are required. The solar-dynamic power systems being investigated for the Space Station rely heavily on the existing technology data base and must by necessity follow a conservative design/development approach to meet the scheduled launch date.

NASA is also pursuing an aggressive, advanced solar dynamic (ASD) technology development program to provide power systems to meet future mission needs. This program will provide significant growth from the solar dynamic power systems being studied for the Space Station with a goal to provide a factor of 5 increase in the specific power over that of the IOC Space Station power system ( 5 to $25 \mathrm{w} / \mathrm{Kg}$ ). These advanced power systems will also be applicable to a wide range of sizes and orbits.
Key elements of the ASD program are to increase operating temperature and efficiency of these systems as well as to develop more efficient and lighter weight components. The program is highly synergistic with the Space Station, the SP-100 and the DOE Terrestrial solar dynamic programs and is focused on developing power systems in the 1025 to $1400 \mathrm{~K}$ temperature range with minimum efficiencies over 25 percent. Missions and systems analysis studies are performed to guide the overall program. Major technology development activities include the heat receiver, advanced energy storage and containment, concentrator, power conversion, microgravity studies, and space environmental effects.

Successful development of a solar dynamic system requires the ability to store energy efficiently during the sun lit portion of the orbit. In this regard, one advantage of solar dynamic systems is that this energy is stored in the form of heat, rather than as electrical energy. This means that losses associated with storage and recovery of the energy, i.e. round trip efficiency and depth of discharge, are applied against a lower or unprocessed form of energy, namely heat, rather than the more valuable processed form of energy, namely work or electricity, as is the case for PV-battery storage systems.

However, this requires the development of thermal energy storage (TES) materials which may absorb heat and experience a rise in temperature (sensible heat storage), of alternately phase change materials (PCM) which experience a meltfreeze cycle (latent heat storage) during each orbit. The latter method of heat storage was assumed in this study.

The purpose of this paper is to show the results of the system mass models used to evaluate effect of PCM properties on the steady state performance and weight of advanced Free Piston Stirling Engine (FPSE) and Closed Brayton Cycle (CBC) Power Conversion Systems. The system models used in this study include a sixteen parameter concentrator/receiver code. The power systems were considered to consist of the following major subsystems: concentrator, receiver (including $P C M)$, heat exchangers, power conversion unit (PCU), power conditioning and controls ( $P C C)$, main radiator, and structure. The PCM properties considered in the system mass model were the melting point, heat of fusion, and density. Overall system optimization studies were conducted for peak cycle temperatures ranging from 900 to $1500 \mathrm{~K}$ and a power conversion module power level of $35 \mathrm{kWe}$. These studies were conducted at the NASA Lewis Research Center as part of the Advanced Solar Dynamic program.

\section{Advanced Solar Dynamic System Studies}

As part of the ASD program system analysis trade studies are used to identify attractive configurations as a function of operating conditions 1 
and to guide component development efforts and the on-going search for TES materials 2,3 which will lead to low heat receiver size for a given power level and thus have a favorable effect on overall system mass. Thermal energy storage candidate materials for which a limited amount of pertinent information has been obtained are shown in Table 1. Note that as data for PCM transport properties (thermal conductivity, thermal diffusivity, specific heat) becomes available it will be possible to evaluate in more detail the impact of the PCM properties on system mass. For example, the high thermal conductivity of the metal PCM will eliminate the need for heat transfer enhancement devices such as tube fins and high surface to volume container configurations. 2 LiF is a well-characterized salt and, as shown in Table 1 , it has a high heat of fusion, density, and melting point. Therefore, Lif was chosen as a benchmark salt for this system study. To permit system studies at peak cycle temperatures ranging to $1500 \mathrm{~K}$, opt imized reference systems were identified under the hypothetical assumption that a series of PCM would be available with melting points ranging from 900 to $1500 \mathrm{~K}$ but all having a heat of fusion and liquid density identical to that of LiF. The computations were then repeated with higher and lower input densities and heats of fusion so that the effect of these PCM properties on minimum system mass as a function of peak cycle temperature could be determined. Both Closed Brayton Cycle and Free Piston Stirling conversion systems were considered as discussed previously. ${ }^{4}$

\section{Brayton Power Conversion System}

A schematic of a Brayton power conversion system is shown in Fig. 1. A parabolic mirror focuses solar energy into the receiver cavity heating the PCM and the PCS working fluid (He-Xe). The PCS working fluid is expanded through a turbine which drives both the compressor and the electrical power generating alternator. The turbine exhaust stream is passed through a recuperative heat exchanger where some of the residual heat is transferred to the compressor exit stream. Downstream from the recuperator (hot side) the turbine exhaust is cooled to compressor inlet temperature in a heat pipe radiator before being recompressed for another pass through the recuperator (cold side), heat receiver, and the gas turbine.

\section{Stirling Power Conversion System}

A schematic representation of the FPSE is shown in Fig. 2. Heat pipes deliver the receiver's heat to the Stirling engine heater head. Alternately a pumped loop liquid metal system $c$ an be used in place of the heat pipes. It is also used to transfer heat from the cold end of the engine to the heat pipe radiator. The operation of this heat pipe radiator is similar to that of the Brayton system, except that the evaporator sections of the heat pipes, which penetrate the heat exchanger duct, have pumped heat transport fluid rather than cycle working fluid flowing over them. In the FPSE the oscillatory motion of the power piston is transformed directly to electrical power in a linear alternator.

\section{Subsystem and Component Trades Studies}

The major contributors to the overall mass of a solar dynamic conversion system are the concentrator and receiver, with the balance being represented by the power conversion unit (PCU), power conditioning and controls (PCC), and structure. The breakdown of the concentrator and receiver mass into their component elements is shown in Fig. 3 for a typical "State of the Art" solar dynamic system. Note that even though the containment vessel and receiver structure mass are greater than that of the PCM, the thermophysical properties of the PCM, such as the heat of fusion, density, and thermal diffusivity, are important drivers of the PCM containment vessel and the overall receiver sizes.

Regarding the concentrator, slope error and optical-thermal coupling of the concentratorreceiver sub-system are important in optimizing system mass, or specific power. The effect of concentrator slope error on an ASD-Stirling system is shown in $\mathrm{Fig}$. 4, which was generated by assuming that a series of PCM with meiting points between 900 and $1500 \mathrm{~K}$ was available, each having thermophysical properties equivalent to those of LiF, as previously stated.

Note that as concentrator surface slope error, $E$, increases, the specific power drops of $f$ sharply, and the peak specific power shifts to lower temperatures. Also, the increase in specific power due to a decrease in mirror surface error from 1.0 to $0.5 \mathrm{mrad}$ is small. Therefore $1.0 \mathrm{mrad}$ was selected as the baseline goal. The break seen at $1400 \mathrm{~K}$ is due to a change in tube and containment wall material.

Figure 5 shows the variation of Brayton System mass (regenerator effectiveness $=0.95$ ) with temperature ratio for three turbine inlet temperatures (TIT). Each point on the three curves represents a local minimum system mass obtained by systematically converging on a cycle pressure ratio which yielded the lowest system mass for the particular temperature ratio. For each curve, as the temperature ratio is increased, system mass first decreases due to increased system efficiency, then after passing through a global minimum (minimum of local pressure ratio minima), increases due to the increasing radiator mass. Note that with increasing TIT the mass versus temperature ratio (i.e., system efficiency) tradeoff curves become flatter. This occurs because the minimum mass points are obtained at increasingly higher efficiencies and also at increasingly higher mean heat rejection temperatures. Hence, a given deviation from the minimum mass temperature ratio will result in a smaller mass change at the higher TIT. Brayton system efficiencies represented in this figure varied from 23.5 to 36 percent as the temperature ratio increased from 2.8 to 4.2 . The $1086 \mathrm{~K}$ TIT represents a condition available with presently available LiF thermal energy storage (TES) material having a melting point of $1121 \mathrm{~K}$. System weight models were generated from SOA technology dating back to the 1960's, except for the assumed concentrator specific weight of $1.22 \mathrm{~kg} / \mathrm{m}^{2}$. A radiator specific mass of $5 \mathrm{~kg} / \mathrm{m}^{2}$ was assumed as was an emissivity of 0.85 .

Figure 6 shows overall stirling system mass with temperature ratio for three heater head temperatures. Stirling system efficiencies ranged from 24 to 38.4 percent as the temperature ratio increased from 2 to 3.6 . System weight and 
performance models were obtained from the target values of the Space Power Free Piston Stirling Engine (FPSE) Program. Just as for the Brayton system, mass first decreases due to increased efficiency and then increases due to the overriding influence of increasing radiator mass. For the FPSE weight algorithm used total masses are lower than for the Brayton system. Note that the minimum mass temperature values occur at lower temperature ratios than for the Brayton system. This occurs because the Stirling engine rejects heat at constant temperature and the mean effective radiator temperature is below the lowest cycle temperature. The Brayton cycle, on the other hand, rejects heat at near constant pressure but at temperatures which decrease from recuperator exit to compressor inlet. Hence, the mean effective radiator temperature is well above the lowest cycle temperature.

The variation in component masses and overall system mass is shown in Fig. 7 for the Brayton closed cycle gas turbine operating at a constant turbine inlet temperature (TIT $=1086 \mathrm{~K}$ ) but variable compressor inlet temperatures, obtained by dividing TIT by the temperature ratio shown. The components shown include: concentrator, receiver, engine plus heat exchangers (recuperator and heat sink), power conditioning ( $P C)$, radiator, and structure. With the assumption of an advanced concentrator having a specific weight of $1.22 \mathrm{~kg} / \mathrm{m}^{2}$, the dominance of the heat receiver on overall system mass is obvious up to higher temperature ratios where the increasing radiator mass causes overall system mass to increase. Note that the overall system mass is a minimum at a temperature ratio of 3.7 , as shown previously.

Figure 8 depicts the variation of component and overall Stirling system mass with temperature ratio for a peak cycle temperature of $1086 \mathrm{~K}$. Components are categorized in the same manner as the Brayton cycle shown previously. Engine mass and performance models were derived as before. Again, the receiver dominates overall system mass until higher temperature ratios are reached, then increasing radiator mass starts to drive up the overall system mass. As mentioned previously, the minimum mass for the Stirling system occurs at temperature ratios significantly lower than for Brayton systems operating at the same PC inlet temperature and overall system mass is lower.

\section{System Mass Sensitivities}

Based on the conceptual designs inherent in the previous studies and incorporating the previously described reasonable extensions of the concentrator and receiver technologies being considered for IOC Space Station, it is now possible to present the advanced technology solar dynamic system mass sensitivities at the $35 \mathrm{~kW} \mathrm{level.}$

The variation of overall system mass with power converter (PC) inlet (i.e., peak cycle) temperature is shown in Fig. 9 for 35 kWe Stirling and Brayton systems. These results also assume that a series of TES materials all having the same heat of fusion $(1044 \mathrm{~kJ} / \mathrm{kg})$ and density $\left(1874 \mathrm{~kg} / \mathrm{m}^{3}\right)$ as Lif but different melting points which are approximately 30 to $35 \mathrm{~K}$ above the PCS inlet temperature are available. The mass and performance models for components of the Brayton and Stirling systems are as described previously.

For both systems, mass decreases until a PCS inlet temperature of $1300 \mathrm{~K}$ is reached after which mass increases due to the heavier tube and TES containment. The break in the curves at $1400 \mathrm{~K}$ is due to a change in tube and containment wall material from $\mathrm{Nb}-\mathrm{IZr}$ to Mo-5Ti-0.1Zr. These numbers are conservative and do not take into account advances in materials.

The figure also shows the LiF reference design point obtained by extending the Space Station technology that was being considered in December 1985 to higher temperatures. The present Space Station design point which reflects an increased conservatism is also shown. These new data bring the Space Station solar dynamic system closer to the photovoitaic results ( 6 to $7 \mathrm{~W} / \mathrm{kg}$ for SD, 5 to $6 \mathrm{~W} / \mathrm{kg}$ for PV).

It is obvious that technological advancements over the present Space Station technology can more than double the system specific power at $1000 \mathrm{~K}$. It is also clear that substantial gains are to be made by increasing system input temperature to about $1300 \mathrm{~K}$. Above that point, present materials limitations and higher reradiation losses increase mass and a point of diminishing returns occurs.

To investigate the potential of other PCMs for achieving further reductions in solar dynamic power conversion system mass, parametric overall system mass ( 35 kWe FPSE) calculations were performed for various PCM heat of fusion, density, and meiting point combinations. The results are plotted in Fig. 10 which shows that to accomplish mass reductions below the Lif parametric curve (dark triangles), either heat of fusion, density, or both would need to be raised. Operation at higher temperatures with a given heat of fusion and density will result in only minor mass reduction up to about $1300 \mathrm{~K}$ after which overall systems mass actually increases for reasons pointed out above.

\section{Concluding Remarks}

The steady state system studies reported here show that the heat of fusion and density of the $P C M$ have a significant effect on solar dynamic power conversion system mass. Since these properties drive the PCM mass and containment vessel size, high PCM heat of fusion and density are more important than high melting point (i.e. peak cycle temperature) in reducing system mass. of course the compatibility of the PCM with its containment material will be of paramount importance, since system reliability over a desired operating life requires that the PCM does not react with the containment walls.

Much additional work needs to be done in characterizing the thermophysical properties of a variety of PCM, including thermal conductivity and diffusivity as well as specific heat since high values of these properties may lead to lighter weight receiver designs. Such receivers will be a key feature of advanced solar dynamic conversion 
systems for a variety of applications ranging from low earth orbit to Martian base missions.

\section{References}

1. Brandhorst, H.W.; Juhasz, A.J.; and Jones, B.I.: "Alternative Power Generation Concepts for Space" NASA TM-88876, October 1986.

2. Lacy, D.E.; Coles-Hamilton, C.E.; and Juhasz, A.J.: "Selection of High Temperature Thermal Energy Storage Materials for Advanced Solar Dynamic Space Power Systems," submitted for Presentation at the 22nd IECEC, Philadelphia, PA, August 10-14, 1987.
3. Misra, A.K. and Whittenberger, D.T.: "Fluoride Salts and Container Materials for Thermal Energy Storage Applications in the Temperature Range 1000-1400K," submitted for presentation at the 22nd IECEC, Philadelphia, PA, August 10-14, 1987 .

4. Dustin, M.0. et a1.: "Advanced Solar Dynamic Space Power Systems Perspectives, Requirements, and Technology Needs," presented at the Solar Energy Conference, Honolulu, Hawaii, March 22-27, 1987.

TABLE 1. - PHASE CHANGE TES CANDIDATES FOR ADVANCED SOLAR DYNAMICS 950 to $1500 \mathrm{~K}$

\begin{tabular}{|c|c|c|c|c|c|c|c|c|c|c|c|c|}
\hline \multirow[t]{2}{*}{ PCM } & \multirow[t]{2}{*}{$\begin{array}{c}\text { Melt } \\
\text { temperature, } \\
K\end{array}$} & \multirow[t]{2}{*}{$\begin{array}{l}\text { Heat of } \\
\text { fusion, } \\
\mathrm{kJ} / \mathrm{kg}\end{array}$} & \multicolumn{2}{|c|}{$\begin{array}{l}\text { Density, } \\
\mathrm{kg} / \mathrm{m}^{3}\end{array}$} & \multicolumn{2}{|c|}{$\begin{array}{l}\text { Thermal } \\
\text { conduct ivity, } \\
\mathrm{J} / \mathrm{cm} \cdot \mathrm{s} \cdot \mathrm{K}\end{array}$} & \multicolumn{2}{|c|}{$\begin{array}{c}\text { Thermal } \\
\text { diffuşivity, } \\
\mathrm{m}^{2} / \mathrm{s}\end{array}$} & \multicolumn{2}{|c|}{$\begin{array}{c}\text { Specific } \\
\text { heat, } \\
\mathrm{kJ} / \mathrm{kg} \cdot \mathrm{K}\end{array}$} & \multirow[t]{2}{*}{$\begin{array}{l}\text { Thermal } \\
\text { density } \\
\mathrm{J} / \mathrm{cm}^{3}\end{array}$} & \multirow[t]{2}{*}{$\begin{array}{c}\text { Volume } \\
\text { change } \\
\%\end{array}$} \\
\hline & & & solid & liquid & solid & liquid & solid & liquid & solid & liquid & & \\
\hline $\begin{array}{l}\mathrm{LiH} \\
\mathrm{LiF}-22 \mathrm{CaF}_{2} \\
\mathrm{NaF}-32 \mathrm{CaF}_{2} \\
\mathrm{LiF} \\
\mathrm{Mg}-\mathrm{Si} \\
\mathrm{NaF} \\
\mathrm{Ca}-\mathrm{Si} \\
\mathrm{NaMgF} \\
\mathrm{Be}_{3} \mathrm{Si} \\
\mathrm{Mg}_{2} \mathrm{Si} \\
\mathrm{Mn}^{-\mathrm{Si}} \\
\mathrm{MgF}_{2}\end{array}$ & $\begin{array}{r}953 \\
1039 \\
1103 \\
1121 \\
1233 \\
1268 \\
1296 \\
1303 \\
1363 \\
1373 \\
1415 \\
1536\end{array}$ & $\begin{array}{r}2582 \\
753 \\
655 \\
1044 \\
1212 \\
789 \\
1111 \\
711 \\
1812 \\
1118 \\
1090 \\
933\end{array}$ & $\begin{array}{l}820 \\
2688.5 \\
2680 \\
2640 \\
\text { (b) } \\
2563.9 \\
\text { (b) } \\
\text { (b) } \\
\text { (b) } \\
1940 \\
\text { (b) } \\
\text { (b) }\end{array}$ & $\begin{array}{l}\text { a } 790 \\
2097.0 \\
\text { (b) } \\
1874.4 \\
\text { (b) } \\
1948.6 \\
\text { (b) } \\
\text { (b) } \\
\text { (b) } \\
1900 \\
\text { (b) } \\
\text { (b) }\end{array}$ & $\begin{array}{l}\text { (b) } \\
\text { (b) } \\
\text { (b) } \\
.0634 \\
\text { (b) } \\
.0435 \\
\text { (b) }\end{array}$ & $\begin{array}{l}\text { (b) } \\
\text { (b) } \\
\text { (b) } \\
.0173 \\
\text { (b) } \\
.0125 \\
\text { (b) }\end{array}$ & (b) & (b) & (b) & (b) & $\begin{array}{c}\text { (b) } \\
1579.0 \\
(\mathrm{~b}) \\
1956 \\
(\mathrm{~b}) \\
1537.4 \\
(\mathrm{~b})\end{array}$ & $\begin{array}{l}\text { (b) } \\
22 \\
\text { (b) } \\
30 \\
(b) \\
24 \\
\text { (b) }\end{array}$ \\
\hline
\end{tabular}

aEstimated value.

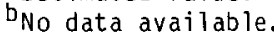




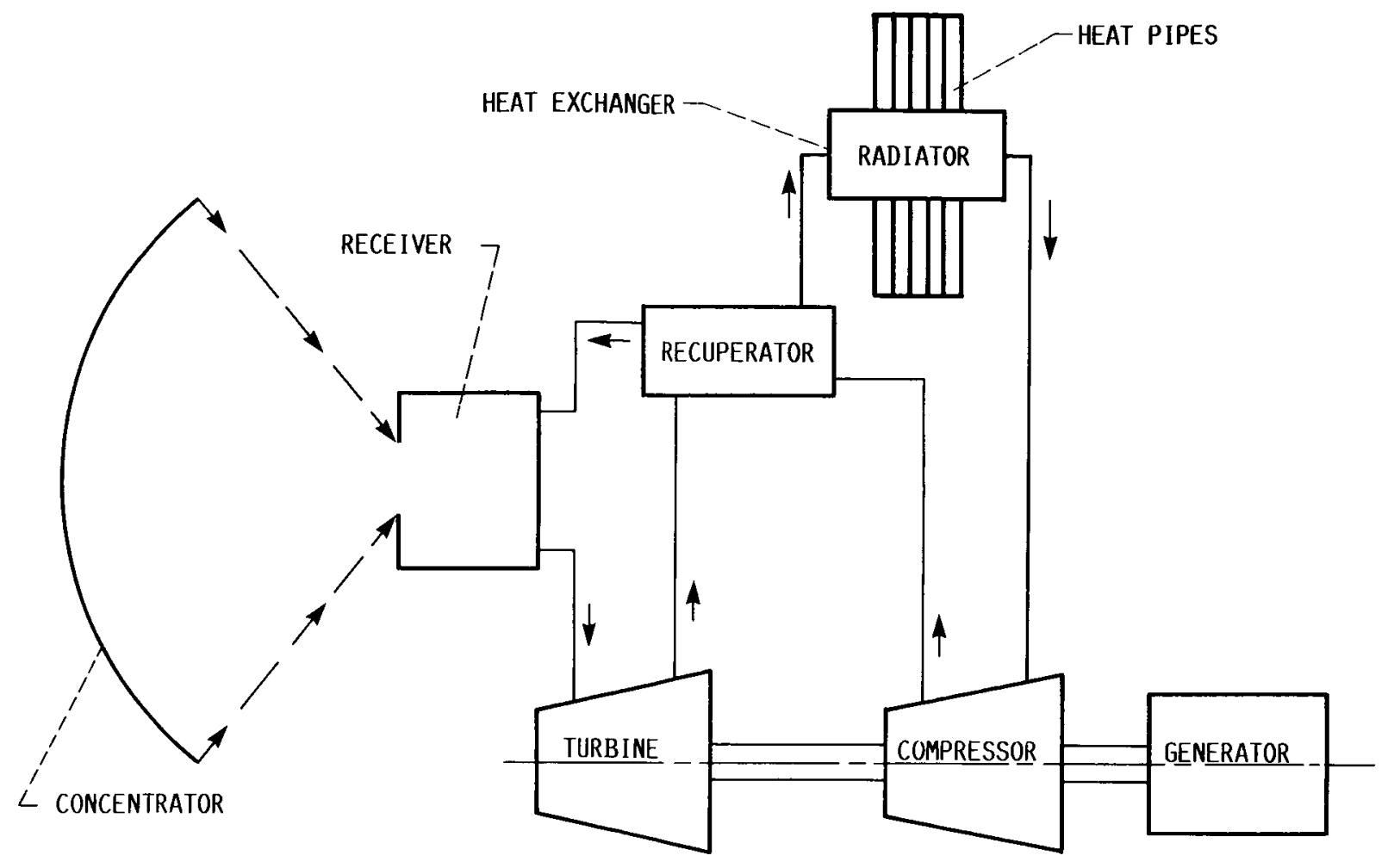

FIGURE 1. - BRAYTON CYCLE SPACE POWER SYSTEM.

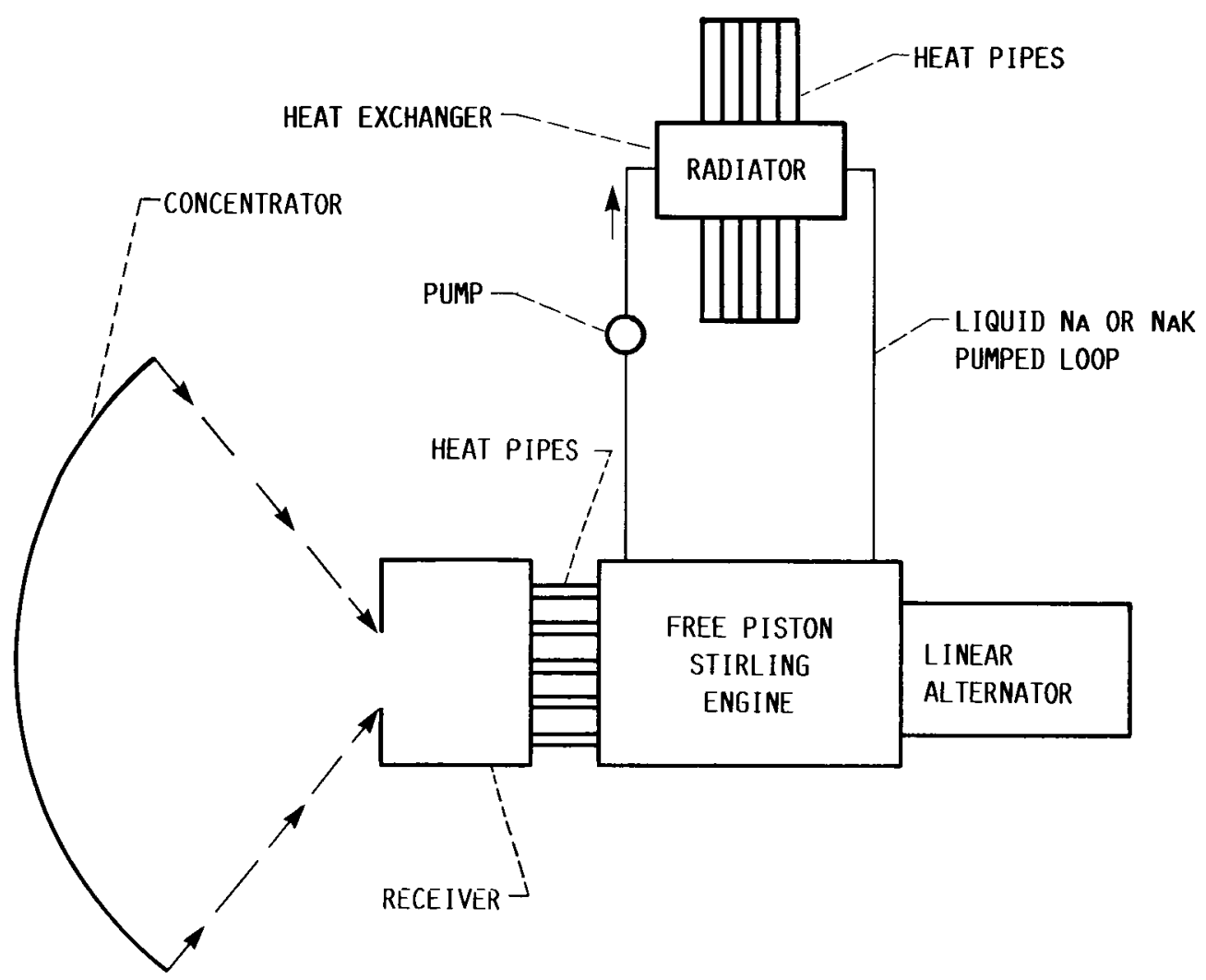

FIgURE 2. - STIRLING CYCLE SPACE POWER SYSTEM. 


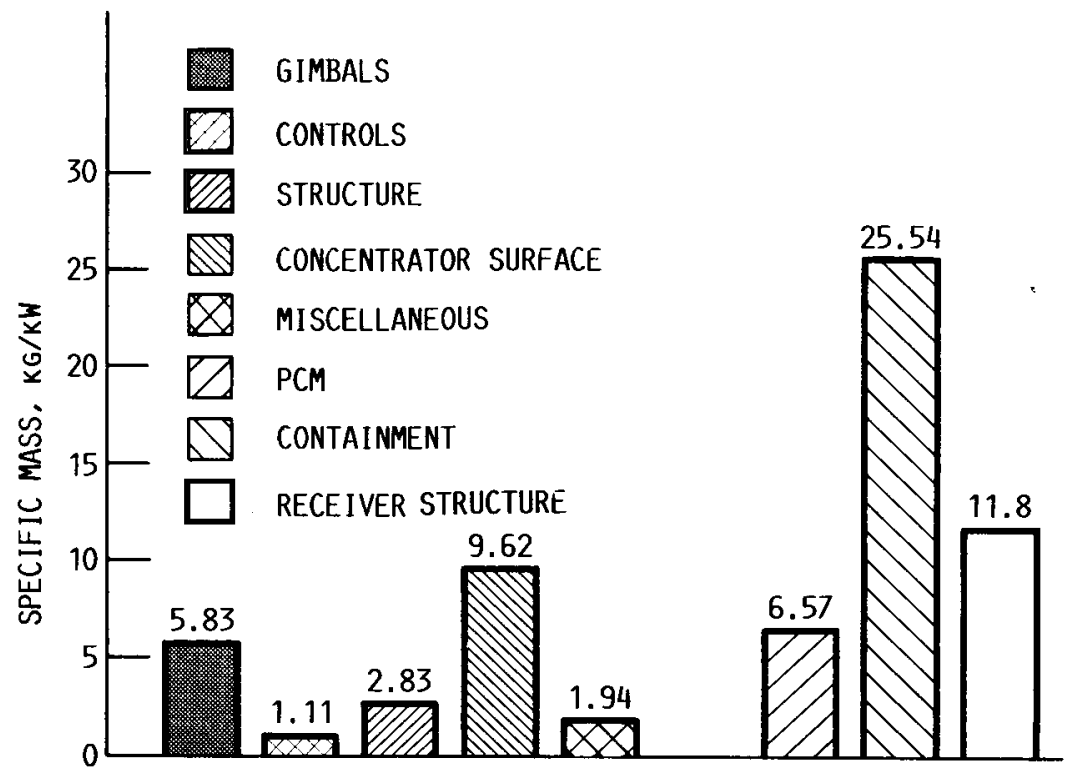

FIGURE 3. - CONCENTRATOR/RECEIVER COMPONENT BREAKDOWN.

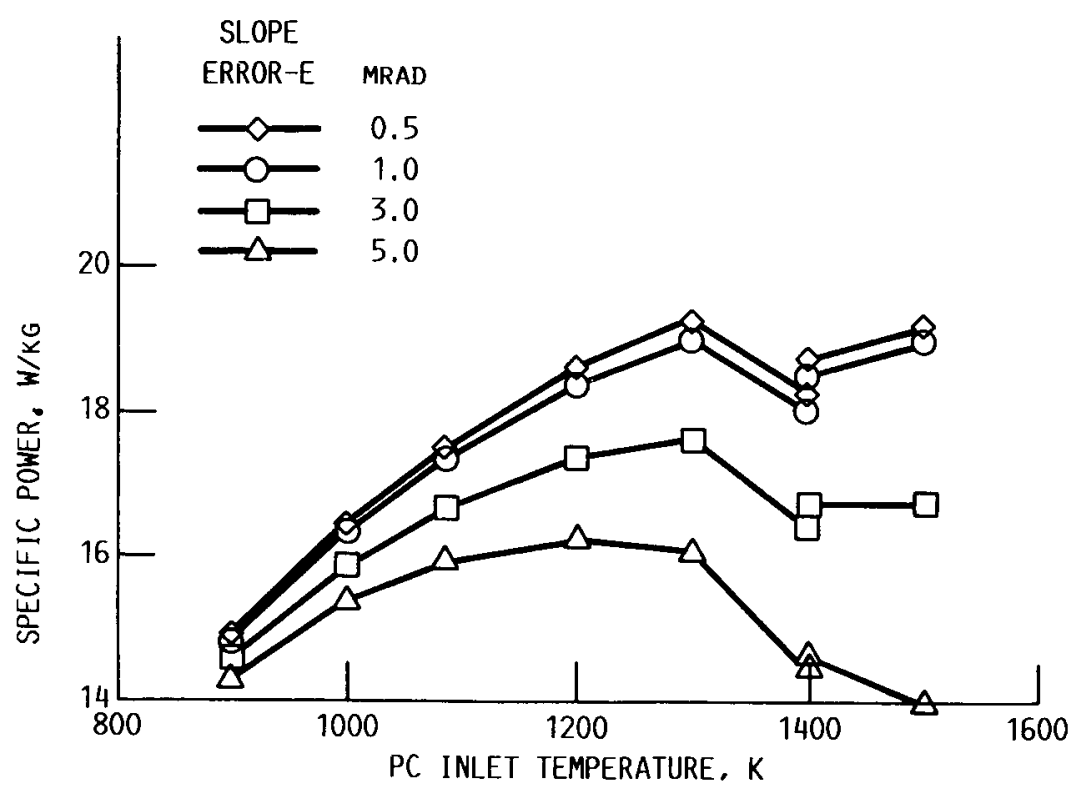

FIGURE 4. - EFFECT OF CONCENTRATOR SLOPE ERROR ON ASD SYSTEM MASS. 


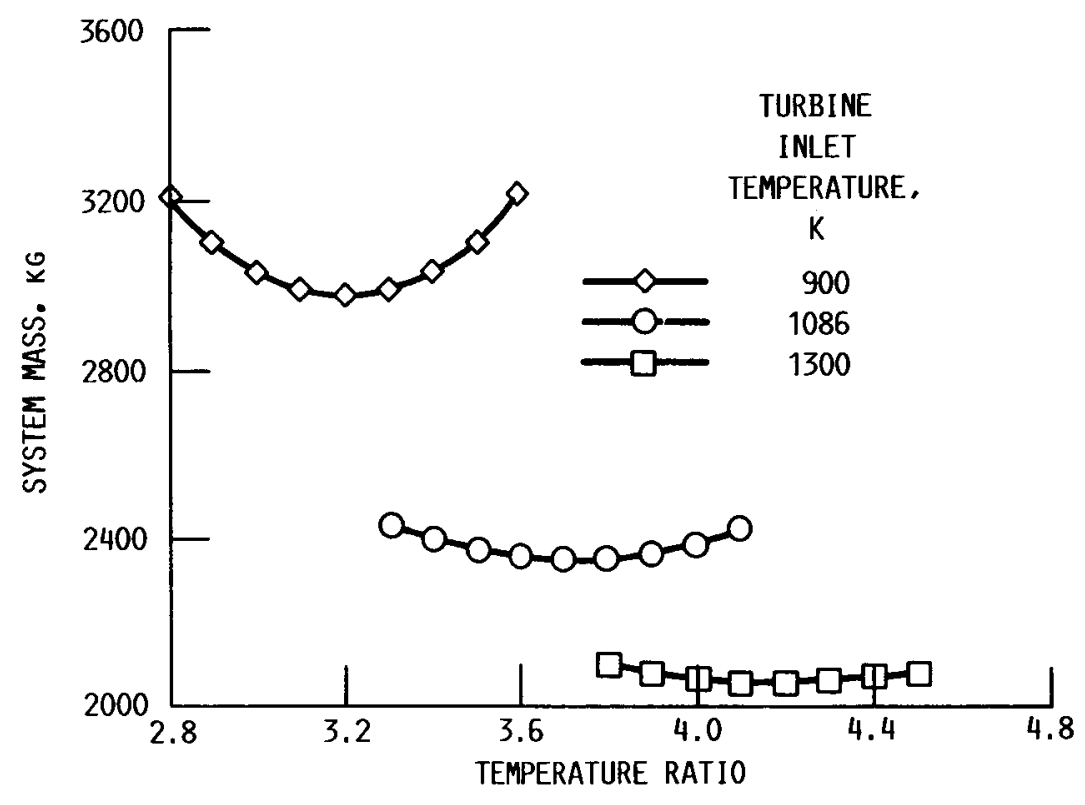

FIGURE 5. - SOLAR BRAYTON SYSTEM MASS SENSITIVITY TO TEMPERATURE RATIO, $35 \mathrm{kWE}$.

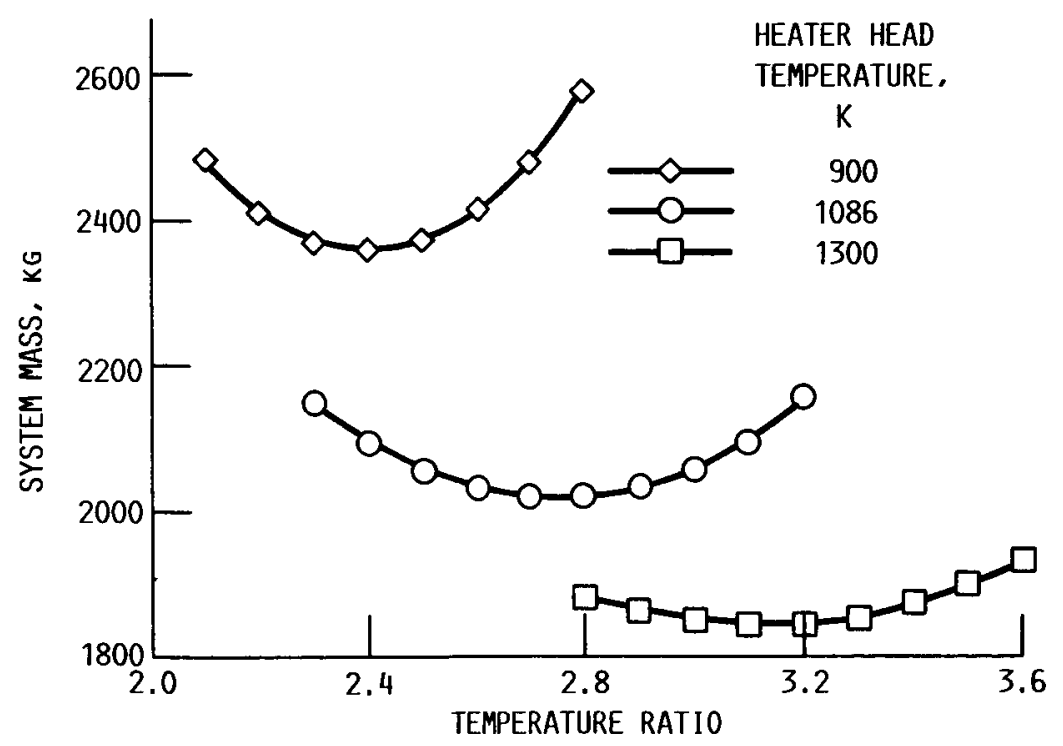

FIGURE 6. - SOLAR STIRLING SYSTEM MASS SENSITIVITY TO TEMPERATURE RATI0, $35 \mathrm{KWE}$. 


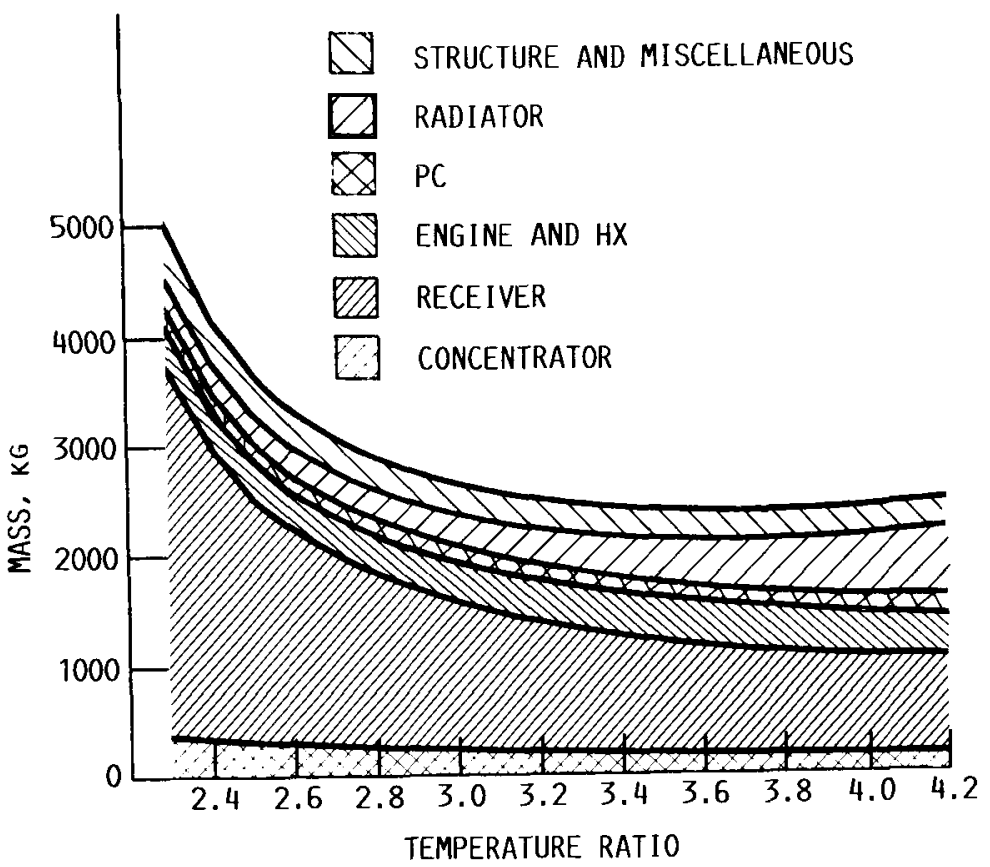

FIGURE 7. - SOLAR BRAYTON COMPONENT PROFILE, $1086 \mathrm{~K}$ TURBINE INLET TEMPERATURE, $35 \mathrm{kWE}$.

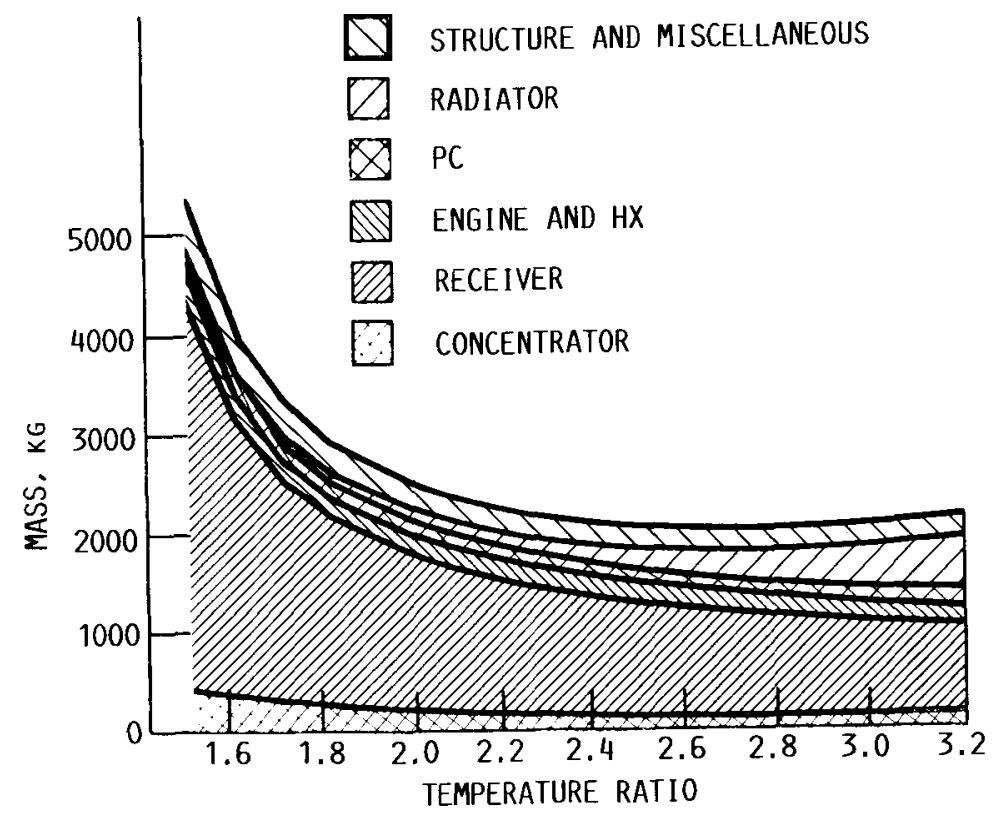

FIGURE 8. - SOLAR STIRLING COMPONENT MASS PROFILE. $1086 \mathrm{~K}$ HEATER HEAD TEMPERATURE, $35 \mathrm{kWE}$. 


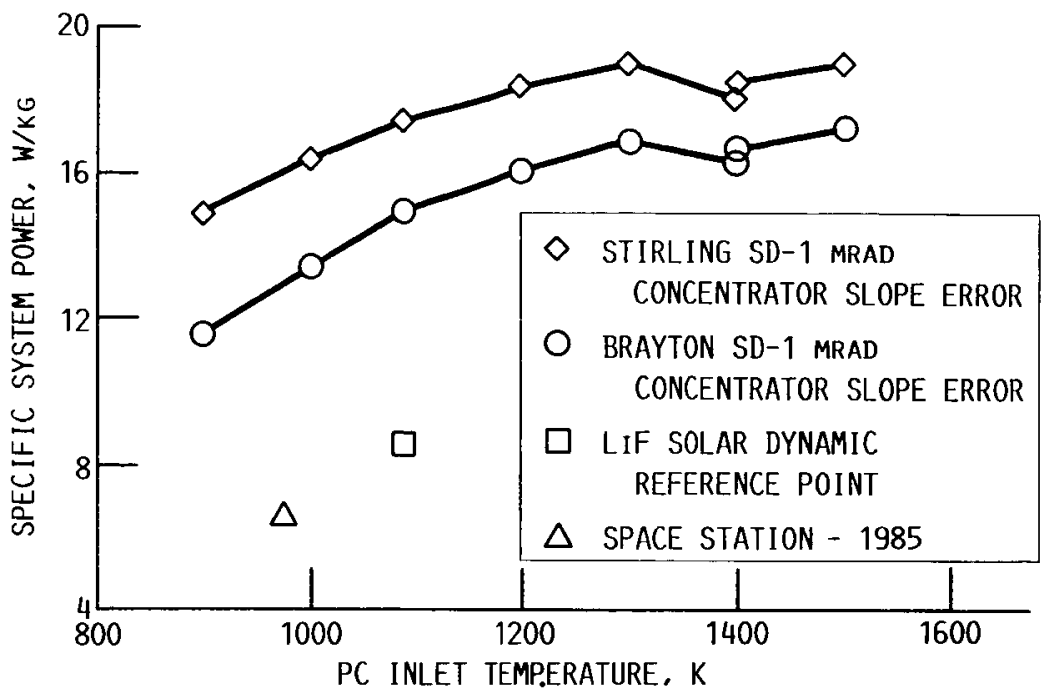

FIGURE 9. - ASD SYSTEM ANALYSIS - 35 KWE, SPECIFIC SYSTEM POWER VERSUS PC INLET TEMPERATURE.

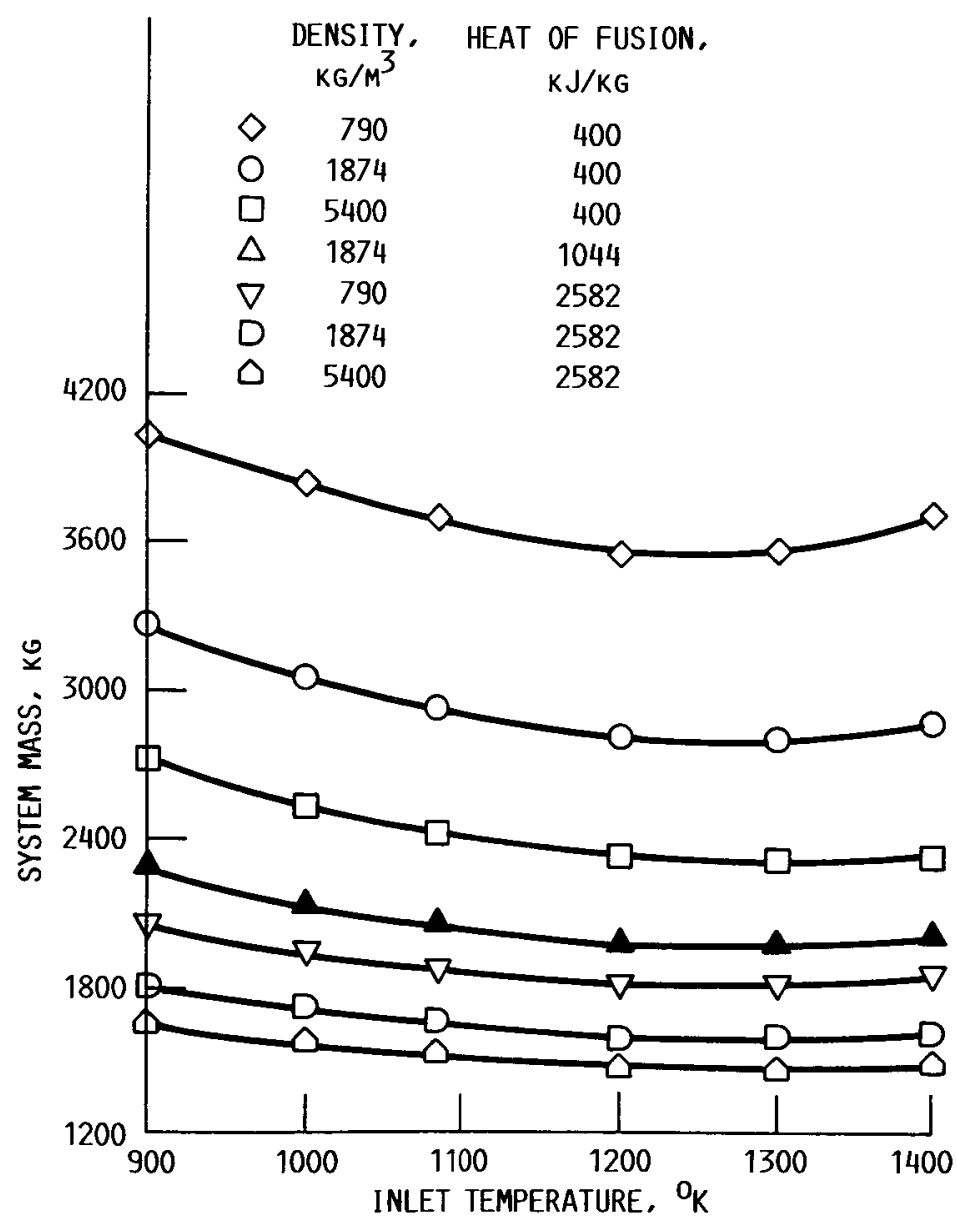

FIGURE 10. - STIRLING SYSTEM ( 35 KWE) MASS AS A FUNCTION OF TEMPERATURE FOR VARIOUS PCM PROPERTY COMBINATIONS. 


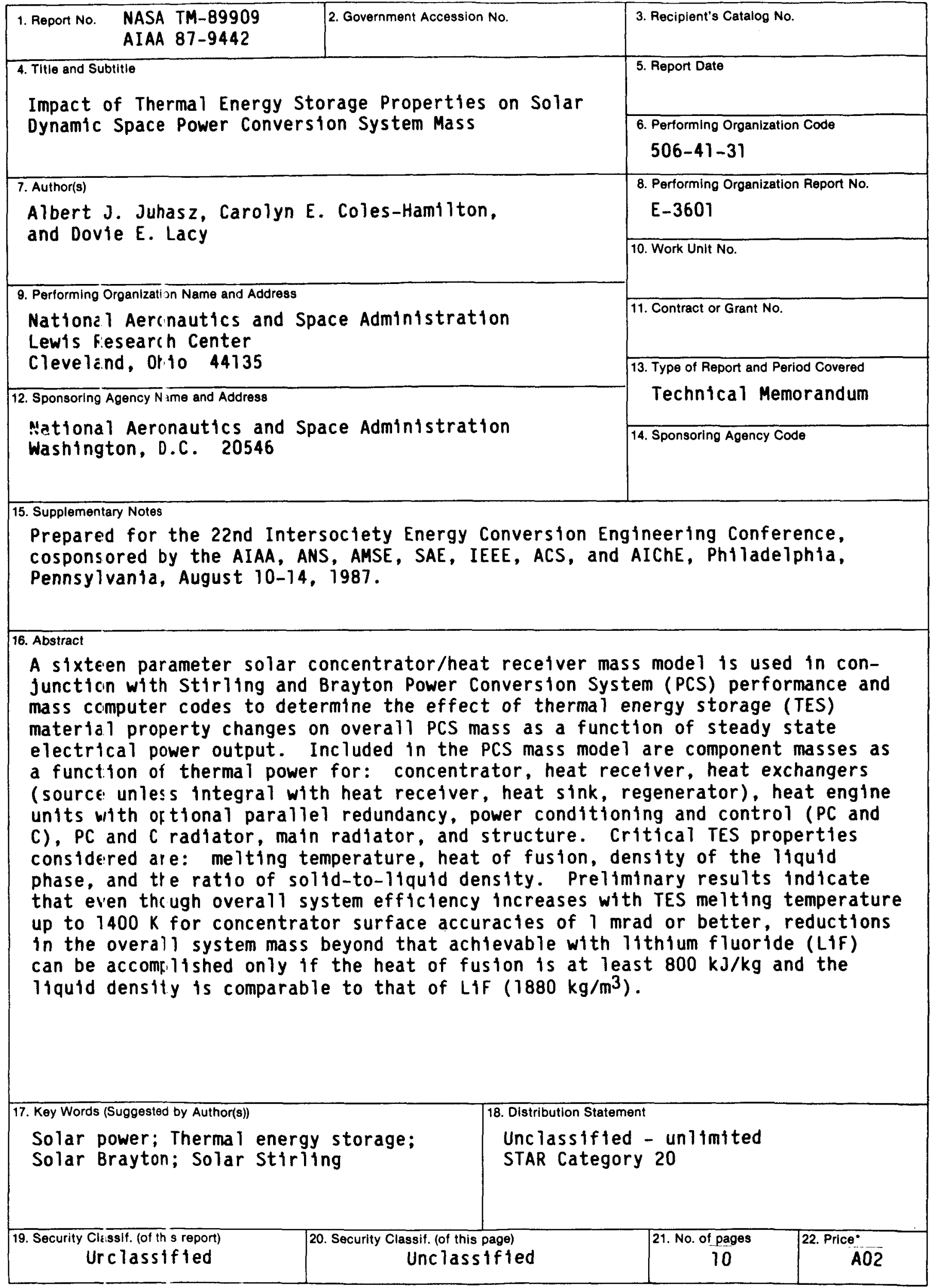

"For sale by the National Technical Information Service, Springfield, Virginia 22161 